\title{
Examining the Predictors of Mental Health Outcomes Among Undergraduate Postsecondary Students in Canada
}

\author{
Brooke Linden \\ University of Regina \\ Rozzet Jurdi-Hage \\ University of Regina
}

\begin{abstract}
Symptoms consistent with mental illnesses such as anxiety and depression are dominant in both prevalence and in severity among North American postsecondary student populations over the past several years. This study examined undergraduate students' self-reported symptoms consistent with two common mental illnesses in a Canadian context, and sheds light on several predictors of students' mental health outcomes, including perceived contextual stressors, coping strategies, and perceived barriers to help-seeking. Data for this investigation were obtained through the completion of self-administered questionnaires from a sample of 209 undergraduate students attending a public western Canadian university. Consistent with previous research completed among postsecondary populations, a considerable proportion of students self-reported symptoms consistent with anxiety and depression. The following variables made unique contributions to the prediction of the severity of students' self-reported symptoms: living arrangement; contextual stressors, such as social/environmental maladjustment, academic achievement, curriculum and academic expectations, time/balance, and financial stressors; styles of coping, including functional/adaptive coping, mental and behavioral disengagement, and substance abuse; and perceived barriers to treatment, including fear of self-discovery and fear of therapy. The implications of these findings for future research and intervention at the postsecondary level are discussed.
\end{abstract}

Keywords: mental illness, contextual stressors, coping, help-seeking, postsecondary students

\section{Introduction}

Mental illness is a leading contributor to the global burden of disease, particularly among youth and young adults (Gore et al., 2011; Whiteford et al., 2013). Over the past decade, mental health deterioration among postsecondary students has become a major concern (e.g., Benton, Robertson, Tseng, Newton, \& Benton, 2003; Cook, 2007; Gallagher, 2013; Hyun, Quinn, Madon, \& Lustig, 2006). Students' struggles with homesickness, loneliness, and difficulties in adjusting to the postsecondary lifestyle have been well documented (e.g., Buote et al., 2007; Byrd \& McKinney, 2012; Cook, 2007; Fritz \& DeMarinis, 2008; Government of Canada, 2006; Jackson, Pancer, Pratt, \& Hunsberger, 2000; Oswald \& Clark, 2003; Pancer, Hunsberger, Pratt, \& Alisat, 2000; Paul \& Brier, 2001; Whitehill et al., 2012). These issues negatively impact students' mental health.

Please address queries to: Rozzet Jurdi-Hage, Department of Sociology and Social Studies, University of Regina, Regina, Saskatchewan, S4S 0A2. Email: rozzet.jurdi@uregina.ca

Brooke Linden is now at the Department of Public Health Sciences, Queen's University in Kingston, Ontario. The survey was conducted with the financial support of the Department of Sociology and Social Studies at the University of Regina. We wish to thank the three anonymous reviewers for several useful suggestions that were incorporated into this manuscript. We thank Philip Linden for his editorial assistance. 
Nearly $90 \%$ of the 43,000 students surveyed in the Spring 2016 National College Health Assessment reported feeling overwhelmed with their workloads in the past 12 months, while over $60 \%$ reported feeling hopeless (American College Health Association [ACHA], 2016). In the same sample, over 13\% of students reported seriously considering suicide within the past year, while $2 \%$ reported suicide attempts, up from 9\% and 1\%, respectively, in the 2013 cycle of this survey. In addition to the high prevalence and severity of symptoms consistent with mental illnesses, several studies have also identified an unmet need for mental health care among the student population (e.g., Givens \& Tjia, 2002; Hyun et al., 2006; Park, Attenweiller, \& Rieck, 2012; Sunderland \& Findlay, 2013; Whitehill et al., 2012; Wilson \& Dean, 2009; World Health Organization, 2013; Wyatt \& Oswalt, 2013). For example, in a study of over 200 students in the United States, the proportion that screened positive for depression but failed to receive treatment ranged from 37\% to 84\% (Eisenberg, Gollust, Golberstein, \& Hefner, 2007). Researchers suggest that perceived barriers contribute greatly to the reported lack of help-seeking among students, including fear of being stigmatized, having little faith in treatment effectiveness, as well as lacking knowledge of available treatment options (e.g., Eisenberg, Downs, Golberstein, \& Zivin, 2009; Eisenberg, Golberstein, \& Gollust, 2007; Park, Attenweiler, \& Rieck, 2012).

The study of mental health and the stigma associated with mental illnesses have gained increasing attention among policy makers and public health professionals in Canada (Government of Canada, 2006; Mental Health Commission of Canada, 2012; Pearson, Janz, \& Ali, 2013; World Health Organization, 2013). Despite continued recognition of these issues among North America's postsecondary student population, gaps remain in the Canadian literature. The vast majority of published studies that explore factors affecting students' mental health are based on American samples. The few available Canadian studies either rely on population-level data (e.g., not specific to postsecondary students) or employ a narrow focus on individual factors, lacking the scope to consider multiple factors simultaneously (e.g., Buote et al., 2007; Jackson et al., 2000; Pancer et al., 2000). At the time the present study was completed, no Canadian study had conducted a multivariate analysis of potential predictors of students' mental health outcomes. While cautious generalization of data between Canada and the United States can occasionally be useful, the vastly different landscapes of institutions of higher learning in each country warrant the need for individual analyses of the postsecondary student milieus. Thus, there remains a need for further research directly addressing factors affecting the mental health of Canadian postsecondary students.

The overall objective of the present study was to provide an analysis of multiple potential predictors of students' mental health outcomes, as indicated by symptoms consistent with depression and anxiety, to develop a more comprehensive understanding of the social context in which Canadian postsecondary students experience mental health and illness. To gain this understanding, the following research questions were examined:

Research Question 1. What contextual stressors do students perceive there to be within the postsecondary milieu, and are these stressors predictive of the severity of self-reported symptoms of mental illness?

Research Question 2. What coping strategies do students employ, and do different methods of coping predict the severity of self-reported symptoms of mental illness?

Research Question 3. What barriers to help-seeking do students perceive there to be, and are these barriers predictive of the severity of self-reported symptoms of mental illness? 
Research Question 4. Taken together, are perceived contextual stressors, coping strategies, and barriers to help-seeking predictive of students' mental health outcomes?

The purpose of the present study was to evaluate a variety of potential predictors of the severity of self-reported symptoms of anxiety and depression among a sample of Canadian postsecondary students. Using a cross-sectional study design, a convenience sample of undergraduate students attending a Western Canadian university was gathered through voluntary completion of a questionnaire distributed during class time. The conceptual framework, outcome and predictor variables, and analysis methods are described below.

\section{Conceptual Framework}

The concept of mental health is broad and inherently complex. The World Health Organization (2013) describes mental health as not simply the absence of illness, but rather a "state of well-being in which every individual realizes his or her own potential, can cope with the normal stresses of life, can work productively and fruitfully, and is able to make a contribution to his or her community" ( $p$. 38). Mental illnesses can result from a multitude of interacting stressors in an individual's life, including those resulting from environmental, social, and physical factors. No single cause exists for the majority of mental illnesses (Mental Health Commission of Canada, 2013). Students' mental health can be affected by a variety of factors, including sociodemographics (e.g., age, sex), contextual stressors, coping strategies, as well as barriers to help-seeking. As such, each of these factors must be considered when determining significant predictors of students' self-reported mental health outcomes.

The conceptual model (Figure 1) used to achieve the goals of this study was based on Pearlin's (1981) stress process theory (SPT). SPT consists of three conceptual domains: the sources of stress, the mediators of stress, and the manifestations of stress (Pearlin, Menaghan, Lieberman, \& Mullan, 1981). In the present study, perceived contextual stressors represent the sources of stress, while coping strategies and perceived barriers to help-seeking represent the mediators of stress. The manifestations of stress are conceptualized in our study as symptoms of anxiety and depression, two broad mental illnesses common in student populations (Iarovici, 2014). Briefly, the conceptual model establishes that stressors, which are mediated by the context in which they are found (e.g., the postsecondary milieu), have the potential to produce a stress response. If stress is not effectively mediated through coping (e.g., use of coping strategies or seeking help), it can lead to a state of distress (e.g., symptoms of mental illness). Wheaton, Young, Montazer, and Stuart-Lahman (2013), from whose research this conceptual model has been adapted, argue that each step between stressors and distress is conditional. That is, the context through which stressors originate can either make a stressor more or less threatening (e.g., stressors that pose a threat to the stability of one's identity, role occupancy, or social location are more likely to precipitate stress than a routine stressor that is often experienced), while coping resources (e.g., seeking social support) may buffer a stressful situation (p. 300). 


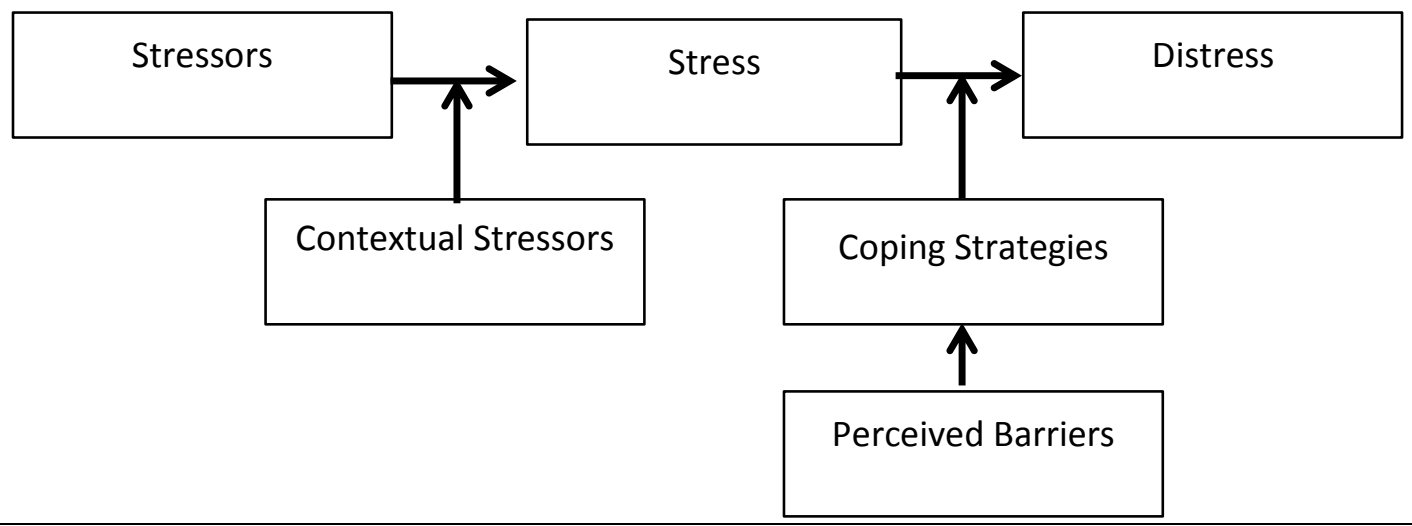

Figure 1. Conceptual Model for Predictors of Postsecondary Students' Mental Health Outcomes

\section{Predictors and Hypotheses}

Several sociodemographic characteristics were considered in our model, including age, sex, marital status, living arrangement, and year of study. A number of contextual stressors were also evaluated, including social/environmental stressors, academic achievement, curriculum and academic expectations, time/balance stressors, and financial stressors. Finally, coping strategies (functional/adaptive coping, mental/behavioral disengagement, and substance abuse) were considered in addition to perceived barriers to help-seeking (fear of self-discovery, fear of therapy, and fear of stigma). Hypotheses are reported below.

\section{Age}

According to the literature, younger students struggle more than their older counterparts with stressful maladjustment when first integrating into the postsecondary environment (e.g., Jackson et al., 2000; Pancer et al., 2000; Paul \& Brier, 2001). Arnett's (2000) concept of emerging adulthood, encompassing ages 18 to 25, provides a theoretical rationalization for these findings (e.g., Arnett, 2000; Iarovici, 2014). Arnett argues that identity formation and consolidation occur during this transitional period where individuals lack role permanence and its associated stability. Individuals who fall within this age period more frequently report struggling with symptoms consistent with mental illness (e.g., Benton et al., 2003; Kessler, Berglund, Borges, Nock, \& Wang, 2005; Sunderland \& Findlay, 2013).

Hypothesis 1. Self-reported symptoms of mental illness will be more severe among younger students.

\section{Sex}

According to the literature, women are more likely to self-report symptoms consistent with mental illness than their male counterparts (e.g., Eisenberg, Gollust, Golberstein, \& Hefner, 2007;

Government of Canada, 2006; Hyun et al., 2006; Pearson et al., 2013). The high prevalence of mental illness among women is of particular importance to this study because women account for $56 \%$ of Canada's postsecondary student population (Statistics Canada, 2015).

Hypothesis 2. Self-reported symptoms of mental illness will be more severe among female students. 


\section{Marital Status}

Marriage has been consistently correlated with better physical and mental health outcomes (e.g., Koball, Moduddin, Henderson, Goesling, \& Besculides, 2010; Margolis \& Myrskylä, 2010; Wood, Goesling, \& Avellar, 2007). This protective effect may be explained by a number of benefits related to marriage that promote health, including increased economic advantages and social support (Koball et al., 2010).

Hypothesis 3. Self-reported symptoms of mental illness will be less severe among participants who are married or in a common-law relationship.

\section{Living Arrangement}

Studies that have examined the relationship between students' living arrangement and their mental health outcomes have reported inconsistent findings (Buote et al., 2007; Eisenberg, Gollust, et al., 2007). As students enter emerging adulthood, parental influence tends to decrease, while peers become a key source for social support, values, and sense of belonging (Irons \& Gilbert, 2005). Thus, students who remain in their childhood home may find it difficult to make a smooth transition into the postsecondary lifestyle lacking the immediate social support of their friends. However, it is also possible that the social support offered by family may produce a buffering effect on students' stress levels. In fact, moving away from one's childhood home has been correlated with feelings of homesickness and loneliness among new students (Paul \& Brier, 2001). Therefore, it is reasonable to assume that students living at home may benefit from the positive influence of familial social support.

Hypothesis 4. Self-reported symptoms of mental illness will be less severe among students living off-campus with their families.

\section{Year of Study}

Students experience a variety of changes to their immediate environment following their transition to university, including shifts in living arrangements, social circles, and access to transportation and regular amenities (e.g., laundry and groceries). Difficulty with adjusting to the postsecondary lifestyle has been identified as a major stressor among new undergraduate students (e.g., Cook, 2007; Oswald \& Clark, 2003; Pancer et al., 2000; Paul \& Brier, 2001).

Hypothesis 5. Self-reported symptoms consistent with mental illness will be more severe among students in an earlier year of study.

\section{Contextual Stressors}

The transition to university is filled with potential sources of stress for students (Oswald \& Clark, 2003). In addition to the stressors associated with social and environmental maladjustment, students will often experience a significant increase in both academic expectations and workload. Difficulty in keeping up with the volume of academic work at the postsecondary level has been cited as a significant source of stress for first-year students in particular (Pancer et al., 2000). Academic achievement and the pressure to succeed have also been reported as significant stressors for students who are underprepared for the increase in academic expectations at the postsecondary level (e.g., Jerema, 2010; Martinello, 2008; Parker, Summerfeldt, Hogan, \& Majeski, 2004). Poorly developed time management and organizational skills can further exacerbate these stressors. Balancing responsibilities to family, social circles, academics, and work can result in role strain, 
particularly for an emerging adult who is still developing the ability to multitask. In addition to balancing academic demands, many students are required to work to pay for expenses as they become accustomed to their increased financial independence (Marshall, 2010). Hyun et al. (2006) found that financial confidence was a significant contributor to students' emotional wellbeing, marking financial strain as another considerable source of stress.

Hypotheses 6-10. The greater stress a student perceives there to be because of a stressor, the more severe his/her self-reported symptoms of mental illness will be.

\section{Coping Strategies}

Research has generally shown that stress can be mediated by employing effective coping strategies (Billings \& Moos, 1981; Byrd \& McKinney, 2012; Carver, Scheier, \& Weintraub, 1989; Noh \& Kaspar, 2003; Pearlin et al., 1981; Taylor \& Stanten, 2007). Coping strategies are used to mitigate feelings of stress, and can be employed in both adaptive and maladaptive ways; that is, individuals can employ both positive and negative methods of coping in attempt to buffer stress. Taylor and Stanten (2007) define adaptive, or positive coping strategies as generally healthful behaviors, marked by "taking direct action or confronting emotional responses to a stressor" or problem, while negative, or maladaptive coping strategies are less constructive and are less likely to culminate in a resolution of the problem, often "marked by avoidance, such as withdrawal or denial" (p. 378). In Byrd and McKinney's (2012) study, students' use of coping mechanisms had the largest influence on mental illness and produced the greatest overall change in mental health outcomes. In the present study, we included seeking social support, planning, positive reframing, and active coping as adaptive coping methods. Maladaptive methods of coping included behavioral and mental (e.g., selfblame, denial) disengagement and substance abuse.

Hypothesis 11. The greater the frequency of coping through functional/adaptive coping mechanisms, the less severe students' selfreported symptoms of mental illness will be.

Hypotheses 12-13. The greater the frequency of coping through behavioral/mental disengagement OR substance abuse, the more severe students' self-reported symptoms of mental illness will be.

\section{Barriers to Help-Seeking}

Within the broader population, only one quarter of youth struggling with mental health issues seek professional care (Wilson \& Deane, 2010). Similar findings have been reported among student populations (e.g., Eisenberg, Golberstein, \& Gollust, 2007; Givens \& Tjia, 2002; Rosenthal \& Wilson, 2008). This disconnect between the need for treatment and unwillingness to seek help may exist because of perceived barriers to help-seeking. Based on Park et al.'s (2012) study, we tested the following potential barriers: fear of stigma, fear of therapy, and fear of self-discovery. Despite efforts to eradicate stigma and foster supportive postsecondary environments, fear of stigma remains one of the largest barriers to help-seeking among students (e.g., Crisp et al., 2005; Givens \& Tjia, 2002; Wilson \& Deane, 2010; Wyatt \& Oswalt, 2013). Fear of therapy and fear of self-discovery have also been frequently reported among student populations, often manifesting as lack of faith in treatment quality and effectiveness (e.g., Eisenberg, Golberstein, et al., 2007; Givens \& Tjia, 2002; Wilson \& Deane, 2010), concern for confidentiality (e.g., Givens \& Tjia, 2002), a lack of perceived need for help (e.g., Eisenberg, Golberstein, et al., 2007; Wilson \& Deane, 2010; Whitehill et al., 2012), and concern over having to admit to struggling with a mental health related issue (e.g., Park et al., 2012). 
Hypotheses 14-16. The more prominent a perceived barrier to help-seeking is to students, the more severe self-reported symptoms of mental illness will be.

\section{Method}

\section{Participants and Instrumentation}

A sample of 209 undergraduate students attending a mid-sized, public university in Western Canada participated in a 25-item, self-administered questionnaire. Invitations to participate were delivered to instructors of all undergraduate classes in the Sociology and Social Studies Department during the fall semester of 2014. Of the 16 classes offered during the time frame, only two did not partake in the study. Questionnaires were distributed during the first 15 minutes of participating classes over a 1 -week period in October by one of the investigators or the class instructor (based on the instructor's preference). Two instructors chose to administer the questionnaires themselves. All participants were assured of anonymity and confidentiality, in addition to their right to withdraw at any time. No incentive was provided. Though a formal response rate was not calculated due to the nonprobabilistic nature of the sampling design, anecdotal information obtained from course instructors revealed that in each participating class, all students completed the questionnaire unless they had already done so in another class. There were no withdrawals. Participating students were enrolled in several faculties, including Arts $(n=103,58.5 \%)$, Education $(n=35,19.9 \%)$, Business Administration $(n=19,10.8 \%)$, Science $(n=8,4.5 \%)$, Kinesiology and Health Studies $(n=6,3.4 \%)$, Fine Arts $(n=4,2.3 \%)$, and Other $(n=1,0.6 \%)$. Approval to complete this study was obtained from the University of Regina's Research Ethics Board (REB\# 2014-178).

Representativeness of the sample to the Fall 2014 undergraduate student body was evaluated by comparing the sample's age, sex, and faculty statistics to known university parameters on these characteristics (Office of Research Planning, 2014). Our sample was overrepresented by females ( $82.7 \%$ of the sample vs. $62.3 \%$ of the population), younger students $(\bar{x}=22.1, S D=5.13$ vs. $\mu=24)$, and students enrolled in the Faculty of Arts (58.5\% of the sample vs. $18 \%$ of the population). Our sample was also compared to the age and sex compositions of the broader Canadian undergraduate student body. In our sample, $47.8 \%$ of undergraduate students were under the age of 20 , compared to $25 \%$ across the country for the 2012-2013 academic year (Statistics Canada, 2014). Finally, our sample was overrepresented by females ( $83 \%$ of the sample vs. $57 \%$ of the national student population; Statistics Canada, 2014). As such, the characteristics of this convenience sample limit the external validity (generalizability) of the findings. However, findings from the current study contribute to the current body of Canadian literature on students' mental health, and address gaps such as the need for multivariate analyses of multiple predictors of students' mental health outcomes. Ideally, trends and themes identified in our study will contribute to larger, more comprehensive studies in the future.

\section{Data Analysis}

Several statistical analyses were undertaken to determine the make-up of the sample and the relationships between factors of concern. All analyses were conducted using IBM SPSS, Version 23. Univariate analyses were undertaken to examine descriptive statistics for all variables. Measures of central tendency and dispersion were computed and data was assessed for issues relating to outliers, missing data, skewness and kurtosis. No significant outliers were found, and the limited amount of missing data did not warrant any adjustment. There were no issues related to the skewness and kurtosis of variables. 


\section{Outcome measures}

Two measurement scales were used to evaluate the frequency with which students had experienced a variety of symptoms consistent with anxiety and depression over the previous 2 -week period. The Generalized Anxiety Disorder seven-item scale (GAD-7) was used to measure symptoms consistent with anxiety, while the Patient Health Questionnaire nine-item scale (PHQ-9) was used to measure those consistent with depression. Participants were asked to indicate the frequency with which they had experienced each of the items on the PHQ-9 and GAD-7 on a Likert-scale ranging from 0 (not at all) to 3 (almost every day) over the past 2 weeks. Participants' responses to the items on each scale were added, with composite scores ranging from 0 to 21 for the GAD-7 and from 0 to 27 for the PHQ9. Higher scores indicated greater severity of symptoms consistent with anxiety and depression, respectively. As previous investigators have successfully done (e.g., Luxton, Skopp, \& Marguen, 2010; Rosemann et al., 2007), we kept these scores as continuous, interval-ratio variables for analysis, as it is always better to use the highest level of measurement (i.e., interval-ratio) whenever possible (Healey \& Prus, 2015; Neuman \& Robson, 2015). Furthermore, the authors of both the GAD-7 and PHQ-9 have confirmed their reliability and validity, as well as increasing use, as severity indices for symptoms of anxiety and depression (Kroenke, Spitzer, \& Williams, 2001; Spitzer, Kroneke, Williams, \& Löwe, 2006).

Both scales have excellent reliability and validity based on vigorous psychometric testing. The PHQ9 has a high internal consistency of $\alpha=0.89$, and a test-retest reliability of 0.84 (Kroenke et al., 2001). In terms of validity, a score of 10 or greater on this scale has a sensitivity and specificity of $88 \%$, with a likelihood ratio of 7.1 (Kroenke et al., 2001). That is to say, a respondent with a major depressive disorder is seven times more likely to have a score of 10 points or higher than a person without. The likelihood ratio increases to 13.6 with a score of 15 or greater (Kroenke et al., 2001). As scores continue to increase, so too does the likelihood of having a depressive disorder. The GAD-7 has an excellent internal consistency of $\alpha=0.92$ and a good test-retest reliability of 0.83 (Spitzer et al., 2006). In terms of validity, authors of the scale report that a score of 10 or higher has a sensitivity of 0.89 and specificity of 0.82 for detecting generalized anxiety disorder (Spitzer et al., 2006). The GAD7 also has good convergent validity, as demonstrated by its correlations with the Beck Anxiety Inventory $(R=0.72)$ and the anxiety subscale of the Symptom Checklist-90 $(R=0.74$; Spitzer et al., 2006).

\section{Predictor variables}

Prior to multivariate analyses, several scales were constructed from our item pools for perceived contextual stressors, coping strategies, and perceived barriers to treatment. Principal components factor analysis was used to determine the dimensionality of the data to identify subsets of items constituting meaningful scales that measured the same underlying construct. The data were checked to ensure all assumptions for the analysis were met; namely, that most interitem correlation coefficients were above 0.30, the Kaiser-Meyer-Olkin (KMO) measure of sampling adequacy was above 0.60, and the Bartlett test of Sphericity was statistically significant. Only factors with an eigenvalue of 1.0 or above were retained for investigation. Scree test and parallel analysis were also used to determine which factors should be retained (Pallant, 2011). The factors were rotated using the varimax (stressors, coping) and promax (barriers) methods (Pallant, 2011). Orthogonalized (uncorrelated) factor scores were then computed using the Anderson-Rubin method (Tabachnick \& Fidell, 2007). Reliability analysis was undertaken on all scales to determine internal consistency using Cronbach's alpha, which measures the extent to which items on a scale evaluate the same underlying construct. The operational definitions of each of the predictor variables considered in our analyses are detailed in Table 1 . Table 2 reports means, standard deviations, interitem correlations and Cronbach's alpha coefficients for all predictor variables (where applicable). 
Table 1. Definitions of Predictor Variables Considered in Analyses

\begin{tabular}{ll}
\hline Variable & Label and Explanation \\
\hline I. Socio- & -"Sex," a discrete, nominal variable. Male is the reference category. \\
demographic & -"Age," a continuous, interval-ratio variable inquiring exact age at the time of the survey. \\
variables & -"Marital Status," a discrete, nominal variable. Single is the reference category. \\
& -"Living Arrangement," a categorical variable. Other than "off campus with family" is the \\
& reference category. \\
& -"Year of Study," a continuous, interval-ratio variable that inquired as to the student's \\
& year of study at the time of survey completion.
\end{tabular}

II. Assessed using items from Burge's (2009) University Student Stress Scale, with revisions Contextual based on other reviewed academic stress instruments (e.g., Rocha-Singh's [1994] stressors

III. Coping mechanisms
Graduate Stress Inventory-Revised). Participants indicated degree of stress each item caused on a 4-point Likert scale. Initial extraction through principal components (PC) produced seven factors $(\mathrm{KMO}=.807$; Bartlett's test $=1,148.68, d f=136, p<.001)$, rotated using varimax. Five factors were extracted, accounting for $62 \%$ of the variance:

- "Social/Environmental," (eigenvalue $=5.26$ ), accounted for $31 \%$ of the variance and was composed of five items (factor loadings): meeting new people/friends (.78), adjusting to campus environment (.67), prepping and delivering presentations (.65), meeting with professors (.65), and participating in class (.65).

- "Academic Achievement," (eigenvalue = 1.91), accounted for $11.3 \%$ of the variance and was composed of four items: witnessing a drop in GPA (.87), receiving poor grades (.82), expectations from self to do well (.63), and waiting for grades (.57).

."Curriculum/Expectations," (eigenvalue $=1.31$ ), accounted for $7.7 \%$ of the variance and was composed of four items: sitting exams (.77), studying for exams (.75), meeting assignment deadlines (.69), and handling the academic workload (.56).

- "Time/Balance," (eigenvalue $=1.12$ ), accounted for $6.6 \%$ of the variance and was composed of two items: lack of time for friends/family and social activities (.78) and balancing work with school (.76).

" Financial Stress," (eigenvalue = 1.00), accounted for $5.9 \%$ of the variance and was composed of two items: taking student loans and having to pay them back (.86) and worrying about money (.77).

Assessed using 12 (of 14) scales from the Brief-COPE inventory (Carver, 1997; Carver et al., 1989). Participants indicated frequency of use for each coping method on a 4-point scale. Initial extraction through PC produced four factors with a number of cross loadings. We ran a second order factor analysis $(\mathrm{KMO}=.670$; Bartlett's test $=361.33, d f=36, p<$ .001; e.g., using scale totals as raw data, and omitting one substance abuse item and the self-distraction items which did not load anywhere), which was rotated using varimax. This yielded three factors with eigenvalue $>1$, which explained $60 \%$ of variance.

"Functional/Adaptive Coping," the first factor (eigenvalue $=2.65$ ), accounted for almost $30 \%$ of variance and was composed of five items (factor loadings): seeking emotional support (.73), seeking instrumental support (.73), planning (.72), positive reframing (.71), and active coping (.70).

-"Mental/Behavioral Disengagement," (eigenvalue $=1.67$ ), accounted for $18.6 \%$ of the variance and was composed of three items (factor loadings): disengagement (.82), selfblame (.81), and denial (.58).

-"Substance Abuse," the final factor (eigenvalue = 1.01), accounted for $12 \%$ of the variance and had a single item with one very high factor loading: using/abusing drugs to distract oneself (.95). 
IV. Barriers Assessed using an abridged version of the Mental Health Treatment Obstacles and Fears to help- $\quad$ inventory (Park et al., 2012). Participants indicated degree of concern with each item on a seeking 4-point Likert scale $(1=I$ would not be concerned and $4=I$ would be very concerned $)$. Initial extraction through $\mathrm{PC}$ produced three factors $(\mathrm{KMO}=.880$; Bartlett's test $=$ $1,003.02, d f=66$ and $p<.001$ ), extracted and rotated using promax. Together, these three factors accounted for $52 \%$ of the variance:

-"Fear of Therapy," or fear of consequences of therapy, (eigenvalue $=4.76$ ), was composed of five items (factor loadings): treatment will make things worse (.81), information I share will not be kept confidential (.77), I will be put on drugs or hospitalized (.66), seeing a therapist will negatively impact my job (.55), and therapy will not work (.44). Factor 1 accounted for almost $40 \%$ of the variance.

.Fear of Self-Discovery," (eigenvalue $=0.82$ ), accounted for $6.8 \%$ of variance and was composed of four items (factor loadings): I will have to admit to a problem that I am not ready to face (.93), what the therapist says will be difficult for me to hear (.68), I will have to relive some unpleasant experiences (.60), and I will have to change how I am currently coping (.56).

-"Fear of Stigma," (eigenvalue = 0.69), was composed of three items (factor loadings): My friends will judge me negatively for seeing a therapist (.74); I will be labelled as crazy (.69); and if I see a therapist, it means something is really wrong with me (.57).

Prior to performing multivariate analyses, the data were assessed to rule out any issues of multicollinearity by examining a correlation matrix. The data were also checked to ensure all assumptions of bivariate and multivariate analyses were met before completing regression. The predictor variables were only weakly correlated with one another (e.g., coefficients under 0.40), indicating that all variables were appropriate for use in regression analyses. Hierarchical multiple linear regression was chosen as the most suitable regression analysis to evaluate the data in the context of our study's objectives. 
Table 2. Summary of Means, Standard Deviations, Cronbach's $\alpha$ Coefficients, and Interitem Correlations for All Variables

\begin{tabular}{|c|c|c|c|c|c|c|c|c|c|c|c|c|c|c|c|c|c|c|c|c|c|}
\hline & $M$ & $S D$ & $N$ & Items & $\alpha$ & 1 & 2 & 3 & 4 & 5 & 6 & 7 & 8 & 9 & 10 & 11 & 12 & 13 & 14 & 15 & 16 \\
\hline 1. Femalea & 0.83 & 0.38 & 208 & - & - & 1.00 & & & & & & & & & & & & & & & \\
\hline 2. Age & 22.10 & 5.13 & 207 & - & - & -0.12 & 1.00 & & & & & & & & & & & & & & \\
\hline 3. Married & 0.16 & 0.37 & 208 & - & - & -0.04 & $0.46^{* * *}$ & 1.00 & & & & & & & & & & & & & \\
\hline 4. Live with familyc & 0.39 & 0.49 & 209 & - & - & -0.08 & -0.12 & $-0.30^{* * * *}$ & 1.00 & & & & & & & & & & & & \\
\hline 5. Year of study & 2.67 & 1.12 & 205 & - & - & -0.03 & $0.30^{* * * *}$ & $0.21^{* *}$ & 0.06 & 1.00 & & & & & & & & & & & \\
\hline $\begin{array}{l}\text { 6. Social/ } \\
\text { Environmental }\end{array}$ & - & - & 207 & 5 & 0.73 & 0.08 & -0.08 & -0.08 & $0.14^{*}$ & -0.07 & 1.00 & & & & & & & & & & \\
\hline $\begin{array}{l}\text { 7. Academic } \\
\text { achievement }\end{array}$ & - & - & 207 & 4 & 0.79 & 0.03 & -0.05 & -0.14 & $0.21^{* *}$ & 0.04 & 0.00 & 1.00 & & & & & & & & & \\
\hline $\begin{array}{l}\text { 8. Curriculum/ } \\
\text { Expectations }\end{array}$ & - & - & 207 & 4 & 0.79 & 0.13 & -0.11 & 0.02 & -0.08 & -0.08 & 0.04 & 0.03 & 1.00 & & & & & & & & \\
\hline 9. Time/Balance & - & - & 206 & 2 & 0.62 & 0.08 & -0.01 & 0.03 & 0.08 & 0.04 & 0.03 & 0.01 & -0.03 & 1.00 & & & & & & & \\
\hline 10. Financial stress & - & - & 203 & 2 & 0.64 & 0.12 & 0.13 & 0.14 & -0.10 & -0.03 & 0.01 & 0.01 & -0.04 & -0.01 & 1.00 & & & & & & \\
\hline $\begin{array}{l}11 . \\
\text { Functional/Adaptive }\end{array}$ & - & - & 198 & 5 & 0.77 & $0.16^{*}$ & 0.13 & 0.04 & -0.12 & 0.03 & -0.04 & $0.21^{* *}$ & 0.00 & 0.14 & 0.14 & 1.00 & & & & & \\
\hline $\begin{array}{l}12 . \\
\text { Mental/Behavioral } \\
\text { disengagement }\end{array}$ & - & - & 207 & 3 & 0.58 & 0.14 & -0.02 & 0.00 & 0.01 & -0.10 & $0.25^{* *}$ & $0.16^{*}$ & 0.14 & $0.28^{* * * *}$ & 0.10 & 0.00 & 1.00 & & & & \\
\hline 13. Substance abuse & - & - & 198 & 1 & - & 0.05 & -0.05 & 0.04 & 0.08 & 0.02 & 0.04 & 0.03 & -0.05 & 0.04 & -0.02 & 0.00 & 0.00 & 1.00 & & & \\
\hline 14. Fear of therapy & - & - & 209 & 5 & 0.80 & -0.08 & -0.05 & 0.01 & -0.02 & -0.04 & 0.08 & 0.11 & -0.02 & -0.04 & 0.30 & -0.02 & $0.21^{* *}$ & -0.04 & 1.00 & & \\
\hline $\begin{array}{l}\text { 15. Fear of self- } \\
\text { discovery }\end{array}$ & - & - & 207 & 4 & 0.81 & 0.06 & -0.06 & -0.11 & $0.15^{*}$ & -0.12 & $0.17^{* *}$ & 0.13 & $0.21^{* *}$ & -0.03 & -0.08 & 0.06 & $0.44^{* * *}$ & 0.00 & 0.01 & 1.00 & \\
\hline 16. Fear of stigma & - & - & 208 & 3 & 0.75 & $-0.14^{*}$ & -0.12 & -0.09 & 0.11 & 0.03 & 0.03 & 0.09 & -0.03 & 0.10 & -0.06 & -0.11 & 0.02 & $0.20^{* *}$ & -0.01 & 0.01 & 1.00 \\
\hline
\end{tabular}

a ${ }^{\mathrm{a}}$ Dummy variable, where $0=$ male (reference category). ${ }^{\mathrm{b}}$ Dummy variable, where $0=$ unmarried (single, separated, divorced, or widowed; reference category). ${ }^{\mathrm{c}}$ Dummy variable, where $0=$ other livin arrangement (alone, with roommates, or in residence; reference category). ${ }^{\mathrm{d}}$ The computed factor scores (Items 6 through 16 ) are standardized to a mean of zero and a standard deviation of 1 (Tabachnick \& Fidell, 2012). ${ }^{*} p<.05 .{ }^{* *} p<.01 .{ }^{* * *} p<.001$. 


\section{Results}

Our first objective was to determine the prevalence and severity of self-reported symptoms consistent with anxiety and depression among our sample. Participants were asked to indicate the frequency with which they had experienced each of the items on the PHQ-9 and GAD-7 on a Likertscale ranging from 0 (not at all) to 3 (almost every day) over the previous 2 -week period. Total scores of 5 and over indicated that symptoms of anxiety and depression were at least mildly present. Cutpoints of 5, 10, and 15 indicated mild, moderate, and severe anxiety on the GAD-7, while cut-points of $5,10,15$, and 20 indicated mild, moderate, moderately severe, and severe depression on the PHQ9. Participants' responses are shown by cut-point in Table 3 .

Table 3. Severity of Depression and Anxiety by Recommended Cut-Points

\begin{tabular}{lcr}
\hline & $F$ & $\%$ \\
\hline Anxiety (GAD-7) & & \\
1. None (0-4) & 44 & 21.3 \\
2. Mild (5-9) & 69 & 33.3 \\
3. Moderate (10- & 51 & 24.6 \\
14) & & \\
$\quad$ 4. Severe (15+) & 43 & 20.8 \\
$\quad$ Total & 207 & 100.0 \\
Depression (PHQ-9) & & \\
1. None (0-4) & 51 & 24.6 \\
2. Mild (5-9) & 64 & 30.9 \\
3. Moderate (10- & 45 & 21.7 \\
14) & & \\
4. Moderately & 31 & 15.0 \\
$\quad$ Severe (15-19) & & \\
5. Severe (20+) & 16 & 7.7 \\
Total & 207 & 100.0 \\
\hline
\end{tabular}

For each scale, the authors recommend using a cut off screening point of 10 to indicate probable mental illness (Kroenke \& Spitzer, 2002; Kroenke et al., 2001; Spitzer et al., 2006). A score of 10 or greater on the PHQ-9 has a sensitivity and specificity of $88 \%$ for major depression (Kroenke \& Spitzer, 2002, p. 2). Sensitivity is also maximized at a cut-point of 10 for the GAD-7, with both sensitivity and specificity over $80 \%$ (Spitzer et al., 2006, p. 1094). Based on these criteria, about $44 \%$ of respondents in our study screened positive for at least mild depression, while about $45 \%$ of respondents screened positive for at least mild anxiety. These findings are comparable to those of previous studies (e.g., Garlow et al., 2008; Martin et al., 2014; Moreno, Jelenchick, \& Breland, 2015; Moreno, Jelenchick, \& Kota, 2013). Descriptive statistics for individual responses to each item in the PHQ-9 and GAD-7 are displayed in Tables 4 and 5, respectively.

The overall mean score for the PHQ-9 was $9.50(S D=6.2)$. Responses to the PHQ-9 mirrored the most recent findings of the National College Health Assessment of Canadian postsecondary students. In our study, nearly $67 \%$ of participants reported "feeling down, depressed, or hopeless" over the past 2 weeks. Nationally, $50 \%$ of students reported they had felt "so depressed it was difficult to function" or had "felt very sad" over the past 2 weeks, while over one quarter reported feeling "hopeless" (ACHA, 2016, p. 31). Over 17\% of our participants reported suicidal ideation at some frequency over the past 2 weeks, with $1.4 \%$ self-reporting having felt this way almost every day. Again, these findings are consistent with the literature. Nationally, over $2 \%$ of students 
reported having self-injured in the past 2 weeks, $3 \%$ reported seriously considering suicide and $0.5 \%$ reported having tried (ACHA, 2016, p. 32).

The most frequently reported symptoms of depression in our study are sleep-related issues. While these items may be symptomatic of sleep disorders rather than depression, it is important to note that when taken in combination with other items on this scale, sleep-related problems can also be indicative of depression. The link between sleep-related issues and depression has been well supported in the literature (e.g., Doane, Gress-Smith, \& Breitenstein, 2015; Ford \& Cooper-Patrick, 2001; Gillin, 1998; Johnson, Roth, \& Breslau, 2006; Wilson et al., 2014).

Table 4. Self-Reported Symptoms Consistent With Depression $(N=207)$

\begin{tabular}{|c|c|c|c|c|c|c|}
\hline \multirow[b]{2}{*}{ Item on Questionnaire } & \multicolumn{4}{|c|}{ Percent Who Reported } & \multirow[b]{2}{*}{$M$} & \multirow[b]{2}{*}{$S D$} \\
\hline & 0 & 1 & 2 & 3 & & \\
\hline 1. Little interest or pleasure in doing things & 49.8 & 32.1 & 12.4 & 5.7 & 0.77 & 0.89 \\
\hline 2. Feeling down, depressed, or hopeless & 33.0 & 43.5 & 17.7 & 5.7 & 0.96 & 0.86 \\
\hline $\begin{array}{l}\text { 3. Trouble falling or staying asleep, or sleeping } \\
\text { too much }\end{array}$ & 20.1 & 26.8 & 28.2 & 24.9 & 1.58 & 1.07 \\
\hline 4. Feeling tired or having little energy & 8.2 & 31.4 & 31.9 & 28.5 & 1.81 & 0.95 \\
\hline 5. Poor appetite or overeating & 24.9 & 25.8 & 27.8 & 21.5 & 1.46 & 1.09 \\
\hline $\begin{array}{l}\text { 6. Feeling bad about yourself, or that you are a } \\
\text { failure or have let yourself or your family down }\end{array}$ & 38.9 & 29.8 & 17.3 & 13.9 & 1.06 & 1.06 \\
\hline $\begin{array}{l}\text { 7. Trouble concentrating on things, such as } \\
\text { reading or watching television }\end{array}$ & 29.7 & 34.9 & 24.9 & 10.5 & 1.16 & 0.97 \\
\hline $\begin{array}{l}\text { 8. Moving or speaking so slowly that other } \\
\text { people noticed-or the opposite-being so } \\
\text { fidgety or restless that you have been moving } \\
\text { around a lot more than usual }\end{array}$ & 69.4 & 19.6 & 9.6 & 1.4 & 0.43 & 0.73 \\
\hline $\begin{array}{l}\text { 9. Thoughts that you would be better off dead } \\
\text { or of hurting yourself in some way }\end{array}$ & 82.8 & 8.6 & 4.8 & 1.4 & 0.30 & 0.73 \\
\hline Total Score & & & & & 9.50 & 6.20 \\
\hline
\end{tabular}


Table 5. Self-Reported Symptoms Consistent With Anxiety $(N=207)$

\begin{tabular}{lcccccc}
\hline & \multicolumn{3}{c}{ Percent Who Reported } & & \\
\cline { 2 - 6 } Item on Questionnaire & 0 & 1 & 2 & 3 & & \multicolumn{2}{c}{$S D$} \\
\hline 1. Feeling nervous, anxious, or on edge & 9.6 & 43.1 & 26.8 & 20.6 & 1.58 & 1.58 \\
2. Not being able to stop or control worrying & 24.4 & 31.1 & 29.2 & 15.3 & 1.35 & 1.35 \\
3. Worrying too much about different things & 10.5 & 32.1 & 34.4 & 23.0 & 1.70 & 1.70 \\
4. Had trouble relaxing & 24.2 & 33.8 & 26.1 & 15.9 & 1.34 & 1.34 \\
5. Being so restless that it is hard to sit still & 38.3 & 34.9 & 15.8 & 11.0 & 1.00 & 1.00 \\
6. Becoming easily annoyed or irritable & 19.6 & 33.5 & 36.8 & 20.1 & 1.47 & 1.47 \\
7. Feeling afraid, as if something awful & 37.8 & 28.7 & 19.1 & 14.4 & 1.10 & 1.10 \\
may happen & & & & & & \\
Total score & & & & & 9.55 & 5.50 \\
\hline
\end{tabular}

The overall mean for the GAD-7 summative score was $9.55(S D=5.5)$. Symptoms of anxiety were slightly more common among this sample of students than symptoms of depression, likely owing to the number of females in the study. Several studies support the link between sex and anxiety, with women being considerably more likely to self-report symptoms of anxiety than their male counterparts (e.g., Eisenberg, Golberstein, et al., 2007; Eisenberg, Gollust, et al., 2007; Garlow et al., 2008; Hyun et al., 2006). Over $90 \%$ of students in the present sample reported feeling nervous, anxious, or on edge during the past 2 weeks, with $20 \%$ having felt this way almost every day. This finding is comparable to nationally-based figures: About one in three (28.5\%) Canadian students report "overwhelming anxiety" during the previous 2-week period (ACHA, 2016, p. 32). Students in our sample also reported restlessness and irritability at fairly high frequencies, and nearly $15 \%$ of participants reported having experienced feelings of fear and dread almost every day over the past 2 weeks.

\section{Multivariate Analysis}

To assess the relative contributions of the hypothesized predictors on the severity of self-reported symptoms of anxiety and depression, hierarchical multiple linear regression analyses were conducted. The results of the two analyses are displayed in Tables 6 and $7 .{ }^{1}$ Each set of predictors was entered as a 'block,' and assessed in terms of its ability to affect the severity of symptoms after controlling for the previous block of variables. Once all blocks were entered, the overall model and relative contribution of each block of variables was assessed in terms of ability to predict the severity of self-reported symptoms among the sample.

\footnotetext{
1 The potential use of the cut off points as our outcome variables was considered at length during the study design phase. Given the level of measurement of the cut-points variables, we ran nested ordinal logistic regression models. Results were very robust: there was no difference in the findings (e.g., statistical significance, direction of association, model fitness, etc.). Ultimately, we chose to operationalize the outcome variables as continuous severity indices, as it is always best to measure at the highest level of measurement. For ease of comparability, the Appendix includes our detailed results of the full ordinal logistic model using the cut-points as outcome variables.
} 
Table 6. Hierarchical Regression Coefficients for Selected Predictors of Severity Index for Self-Reported Symptoms of Depression

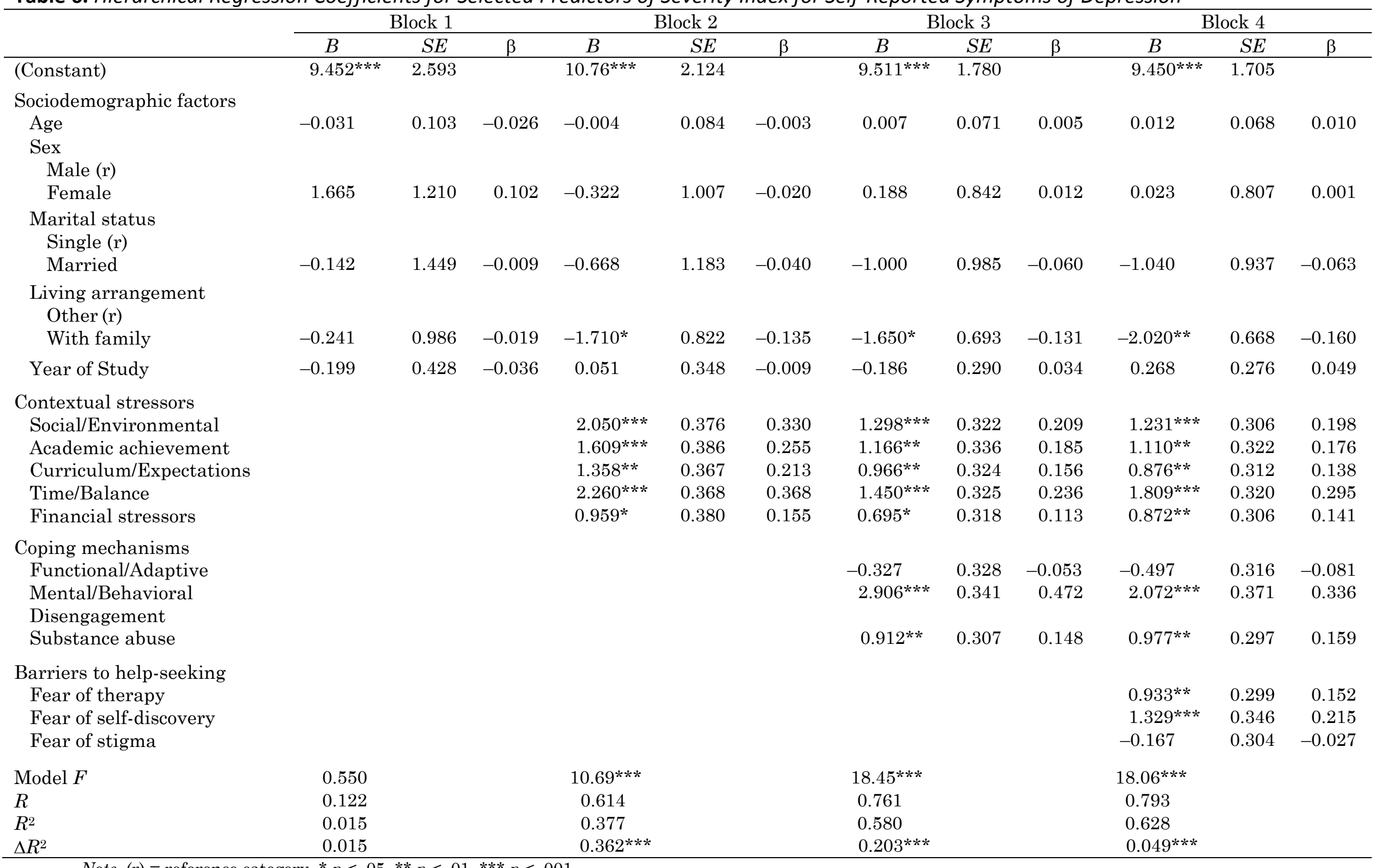
Note. $(\mathrm{r})=$ reference category. ${ }^{*} p<.05 .{ }^{* *} p<.01 .{ }^{* * *} p<.001$. 


\section{Severity of symptoms of depression}

As illustrated in Table 6, $R$ was different from zero at the end of each block, indicating that each group of variables influenced the overall model. Blocks 2 through 4 were statistically significant. After all predictors had been entered into the equation (Model 4), $R^{2}$ was 0.628 with $F=18.06, p<$ .001 , indicating that $62.8 \%$ of the variability in the severity of students' self-reported symptoms consistent with depression was predicted by the selected sociodemographic variables, contextual stressors, coping strategies, and perceived barriers to help-seeking.

In Block 1, the sociodemographic variables were entered. None of these predictors made a unique contribution to the model. After the Block 2 variables were included, the overall model explained $37.7 \%$ of the variance in the severity of symptoms consistent with depression $\left(F=10.69, p<.001, R^{2}\right.$ $=0.377)$. After entering the contextual stressors variables, the sociodemographic variable Live with Family became statistically significant, and inversely related to the dependent variable $(B=-0.135$, $p<.05$ ). This provides support for Hypothesis 4. Alone, the contextual stressors explained $36.2 \%$ of the total variance, after controlling for the effects of the sociodemographic variables $\left(\Delta R^{2}=0.362, p<\right.$ .001). After controlling for the sociodemographic variables, all contextual stressors were found to be significantly and positively related to the dependent variable, with the Time/Balance $(B=0.368, p<$ $.001)$ and Social/Environmental $(B=0.330, p<.001)$ stressors making the greatest impacts. These results provide support for Hypotheses 6 through 10.

After the Block 3 variables were included, the overall model explained $58 \%$ of the total variance in the severity of symptoms consistent with depression $\left(F=18.45, p<.001, R^{2}=0.580\right)$. Coping strategies, therefore, explained $20.3 \%$ of the total variance after controlling for the effects of the sociodemographic and contextual stressors variables $\left(\Delta R^{2}=0.203, p<.001\right)$. As predicted by Hypotheses 12 and 13, Mental/Behavioral Disengagement $(B=0.472, p<.001)$ and Substance Abuse $(B=0.148, p<.01)$, which exemplify maladaptive coping strategies, were significantly and positively related to the dependent variable, after controlling for the sociodemographic and contextual stressors variables. While Functional/Adaptive coping did not make a unique contribution to the model, and therefore, did not provide support for Hypothesis 11, the predictor was inversely related to the dependent variable, as expected. The Live with Family variable and contextual stressors retained their significance in Block 3, albeit slightly less so in the case of Academic Achievement $(B=0.185, p$ $<.01)$.

After the Block 4 variables were included, the overall model explained $62.8 \%$ of the total variance in the severity of symptoms of depression $\left(F=18.06, p<.001, R^{2}=0.628\right)$. Barriers to help-seeking, therefore, explained about $4.9 \%$ of the total variance, after controlling for the effects of sociodemographics, contextual stressors, and coping strategies $\left(\Delta R^{2}=0.049, p<.001\right)$. In Block 4 , the sociodemographic variable Live with Family increased in significance, maintaining its inverse relationship with the dependent variable $(B=-0.160, p<.01)$. All contextual stressors retained their significance levels, except for Financial Stressors which increased in significance $(p<.01)$. The Time/Balance $(B=0.295, p<.001)$ and Social/Environmental stressors $(B=0.198, p<.001)$ continued to make the greatest contributions of the contextual stressors, though Mental/Behavioral Disengagement made the greatest impact to the overall model $(B=0.336, p<.001)$. Substance Abuse also retained its significance in the final block $(p<.01)$, while Functional/Adaptive coping remained non-significant. Of the three barriers to help-seeking, both Fear of Therapy and Fear of SelfDiscovery were significantly and positively related to the dependent variable, after controlling for the sociodemographics, contextual stressors, and coping strategies, with Fear of Self-Discovery making the largest impact of the barriers, and the third-largest impact of all variables in the model $(B=0.215, p<.001)$. Fear of Stigma was not statistically significant. These findings provide support for Hypotheses 14 and 15, but not 16. 
In summary, students who perceived more stress resulting from each of the contextual stressors experienced more severe symptoms of depression. Similarly, students who frequently engaged with maladaptive coping strategies, such as Mental/Behavioral Disengagement and Substance Abuse, and who indicated a Fear of Therapy and Fear of Self-Discovery experienced more severe symptoms. Finally, self-reported symptoms of depression were less severe among students living off campus with their families.

\section{Severity of symptoms of anxiety}

As illustrated in Table 7, $R$ was different from zero at the end of each block, indicating that each group of variables influenced the overall model. Blocks 2 through 4 were statistically significant. After all predictors had been entered into the equation (Model 4), $R^{2}$ was 0.596 with $F=15.77, p<$ .001 , indicating that $59.6 \%$ of the variability in the severity of students' self-reported symptoms of anxiety was predicted by the selected sociodemographic variables, contextual stressors, coping strategies, and perceived barriers to help-seeking.

In Block 1, the sociodemographic variables were entered. Only sex made a unique contribution to the model $(B=0.169, p<.05)$. Alone, sex explained $3.3 \%$ of the total variance in the severity of symptoms of anxiety. After the Block 2 variables were included, the overall model explained $40.9 \%$ of the variance in the severity of symptoms consistent with anxiety $\left(F=12.24, p<.001, R^{2}=0.409\right)$. Sex became non-significant after entering the contextual stressors. Alone, the contextual stressors variables explained $37.6 \%$ of the total variance, after controlling for the effects of the sociodemographic variables $\left(\Delta R^{2}=0.376, p<.001\right)$. All the contextual stressors were found to be significantly and positively related to the dependent variable after controlling for the sociodemographic variables, with Time/Balance $(B=0.371, p<.001)$ and Academic Achievement $(B=$ $0.319, p<.001)$ making the greatest impacts. These results provided support for Hypotheses 6 through 10 .

After the Block 3 variables were included, the overall model explained $56.6 \%$ of the total variance in the severity of symptoms of anxiety $\left(F=17.48, p<.001, R^{2}=0.566\right)$. Coping strategies, therefore, explained $15.8 \%$ of the total variance after controlling for the effects of the sociodemographic and contextual stressors $\left(\Delta R^{2}=0.158, p<.001\right)$. Functional/Adaptive coping $(B=0.126, p<.05)$ was statistically significant, but unexpectedly, was positively related to the dependent variable. Thus, Hypothesis 11 was not supported. As predicted by Hypothesis 12, Mental/Behavioral Disengagement was significantly and positively related to the dependent variable $(B=0.426, p<.001)$. Though Substance Abuse did not make a unique contribution to the model, and therefore, did not provide support for Hypothesis 13, the predictor was positively related to the dependent variable, as expected. The contextual stressors retained their significance in Block 3, albeit slightly less so in the case of Financial Stressors $(B=0.105, p<.05)$. 
Linden \& Jurdi-Hage, 2017

Table 7. Hierarchical Regression Coefficients for Selected Predictors of Severity Index for Self-Reported Symptoms of Anxiety

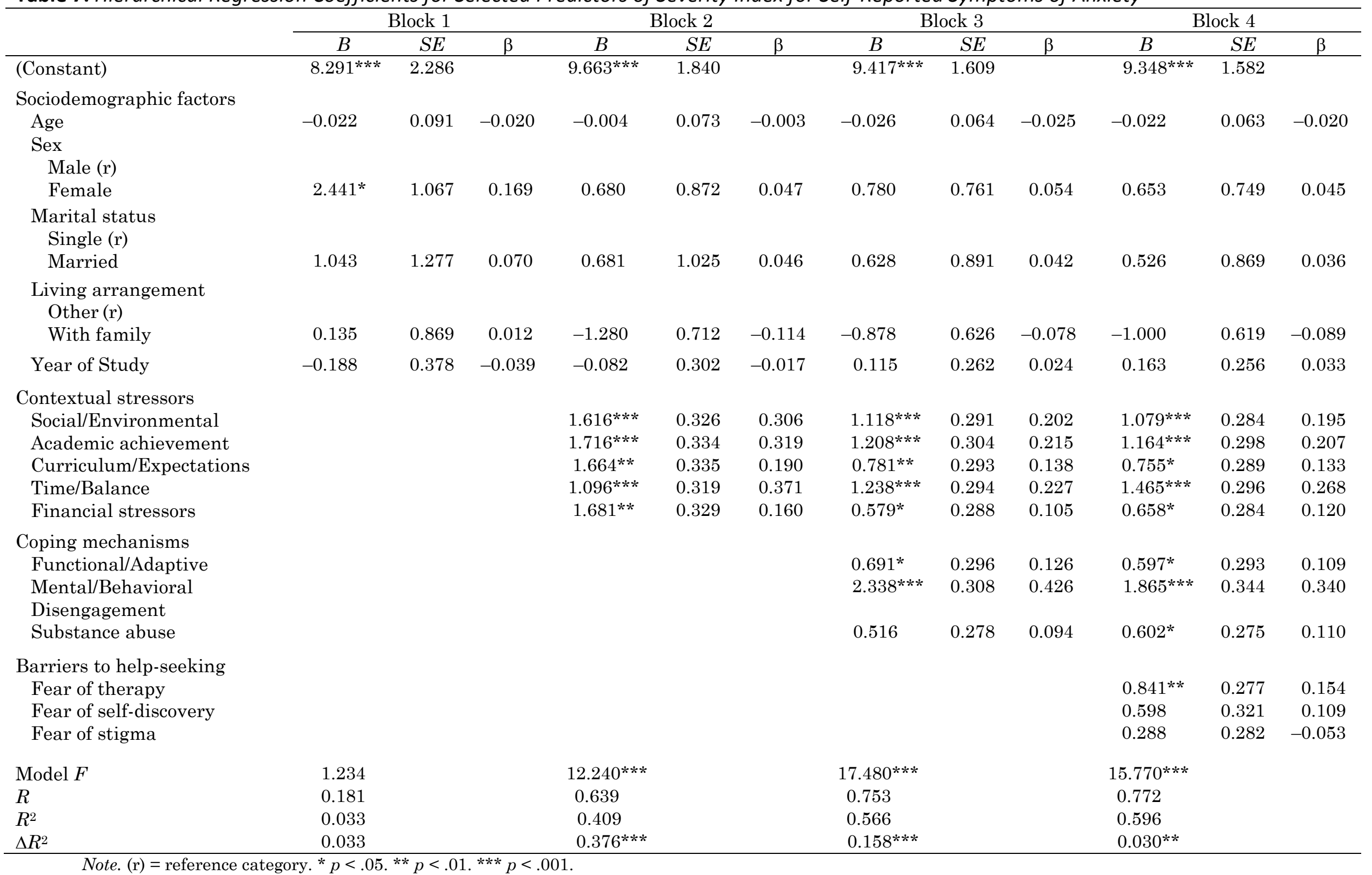


In summary, students who perceived more stress resulting from each of the contextual stressors experienced more severe symptoms of anxiety. Students who frequently engaged with maladaptive coping strategies like Mental/Behavioral Disengagement and Substance Abuse experienced more severe symptoms of anxiety. Unexpectedly, students who employed Functional/Adaptive coping mechanisms also experienced more severe symptoms of anxiety. Finally, students who indicated a Fear of Therapy also demonstrated more severe symptoms consistent with anxiety.

\section{Discussion}

The results from the present study indicated that several students in the sample suffered from symptoms consistent with anxiety and/or depression. Using the recommended cut-point of a score of 10 or greater on each scale, $44 \%$ of students screened positive for depression, while $45 \%$ screened positive for anxiety. While high, these proportions are comparable to those found in previous studies. For example, Benton et al. (2003) found that nearly half of the postsecondary students included in their sample met DSM-IV criteria for at least one mental illness during the previous year. Similarly, Eisenberg, Golberstein, et al. (2007) reported that almost 30\% of students in their study screened positive for either depression or anxiety. Using the PHQ-9 as a screening tool, Moreno et al. (2015) found that $47 \%$ of students in their sample screened positive for at least mild depression, while Moreno et al. (2013) found that 39\% of their sample screened positive for depression. In Martin, Usdan, Cremeens, and Vail-Smith's (2014) study, 21\% screened positive for anxiety on the GAD-7, while $18 \%$ screened positive for depression on the PHQ-9. Although these last estimates are considerably lower than ours are, participants in Martin et al.'s (2014) study were recruited based on their risk for disordered gambling, rather than anxiety or depression, probably reflecting methodological differences in research. Responses to individual items on the PHQ-9 and GAD-7 in the present study were comparable to nationwide data on the physical and mental health of Canadian postsecondary students (ACHA, 2016). The overall mean scores on each scale (9.50 and 9.55 on the PHQ-9 and GAD-7, respectively) were similar to those reported in previous studies using the same scales to screen for cases of anxiety and depression (e.g., Garlow et al., 2008; Moreno et al., 2015).

A variety of potential predictors of students' mental health outcomes was examined in the present study, including contextual stressors, coping strategies, and perceived barriers to help-seeking. Our study assessed the predictive validity of our conceptual model in relation to the severity of undergraduate students' self-reported symptoms of depression and anxiety in two separate regression models. Overall, the regression analyses produced strong models accounting for nearly $63 \%$ and $60 \%$ of the total variance in the severity of symptoms of depression and anxiety, respectively.

Mental/behavioral disengagement, a maladaptive coping strategy, was the most influential predictor of students' mental health outcomes in both models. Substance abuse was also a significant predictor of more severe symptoms of depression and anxiety. These findings are consistent with previous studies, which have shown that maladaptive coping often results in worsening mental health issues, as opposed to mediating them (e.g., Byrd \& McKinney, 2012; Carver et al., 1989). More adaptive coping strategies, such as functional/adaptive coping encourage healthy adjustment and mediate mental distress (e.g., Hunt \& Eisenberg, 2009; Irons \& Gilbert, 2005; Whitehill et al., 2012). As in previous studies (e.g., Byrd \& McKinney, 2012; Hefner \& Eisenberg, 2009; Taylor \& Stanten, 2007), functional/adaptive coping had an inverse (though non-significant) relationship with the severity of symptoms of depression. However, it held a significant, positive relationship with the severity index for anxiety, suggesting that even the use of adaptive coping methods may increase a person's anxiety. Dwelling on an issue or unsuccessfully attempting to resolve it can produce even more 
stress, exacerbating symptoms associated with anxiety (Carver et al., 1989). Additionally, reaching out to friends or family for social support may result in increased stress if the advice given is unhelpful or misinformed. Seeking social support may also have a negative effect if one is met with stigma due to divulging a struggle with mental health-related issues.

For both the depression and anxiety models, time/balance stress was the second most influential predictor of the severity of symptoms consistent with mental illness. Students face time management challenges both in and outside of the academic setting (e.g., work, social engagements, relationships with friends, family, etc.). Students in our sample identified lack of time for friends, family, and social obligations, as well as balancing academic and work obligations as significant sources of stress, mirroring national level data that young adults between the ages of 15 and 24 view managing their time between multiple obligations as a significant source of stress (Government of Canada, 2006). In the anxiety model, academic achievement was a close runner up to time/balance. These findings are consistent with the literature, where academic self-confidence has been identified as a significant predictor of mental health outcomes in addition to being a major source of stress for students (e.g., Byrd \& McKinney, 2012; Iarovici, 2014; Pancer et al., 2000). Social/environmental stress was the second-most influential predictor of the contextual stressors variables for the depression model, and had the fourth-highest impact overall on both models. This finding is consistent with the fact that adjusting to the postsecondary environment can often be an exceedingly stressful experience for students (e.g., Byrd \& McKinney, 2012; Cook, 2007; Jackson et al., 2000; Oswald \& Clark, 2003; Pancer et al., 2000). In particular, Oswald and Clark (2003) note that students new to postsecondary education often find the transition to be the most stressful adjustment phase in their life. For both models, all contextual stressors made significant, unique contributions to predicting the severity of symptoms consistent with anxiety and depression. These findings suggest that students at this university struggled with perceived contextual stressors within the postsecondary milieu.

Fear of self-discovery was the most influential of the three barriers to help-seeking, and the third most influential predictor of the severity of symptoms consistent with depression. Although the variable was not a statistically significant predictor in the anxiety model, it maintained a positive relationship with this dependent variable, indicating that the greater the fear of self-discovery, the poorer the mental health outcome. This barrier included items such as fear of having to relive unpleasant experiences, having to alter current methods of coping, and discovering that something is really wrong with one's mental health. As help negation is symptomatic of depression, it is not surprising that fear of discovering more about one's mental state is a significant barrier to treatment, as well as a significant predictor of the severity of symptoms consistent with depression.

Fear of therapy was a significant predictor of the severity of symptoms for both models. The items combined to create this variable consisted of doubts regarding confidentiality, fear that issues would be worse than one first thought, fear of being placed on medication or being hospitalized, lack of faith in treatment effectiveness, and fear that seeking professional treatment would negatively impact future career or educational opportunities. This is consistent with Givens and Tjia's (2002) finding that high-achieving students reported several of these items as barriers to seeking treatment. Threat of academic jeopardy in particular was found to be an important obstacle for medical students considering treatment for mental illness. Additionally, Eisenberg, Golberstein, et al. (2007) found that students reported concerns that treatment would not help, a fear of being hospitalized, and concern for privacy. The final barrier, fear of stigma, was not statistically significant in either model and shared an inverse relationship with the dependent variable, contrary to our hypothesis. This finding may indicate that postsecondary institutions' efforts towards eradicating the stigma surrounding mental illness have been successful. It may also be indicative of students deciding to 
seek help for fear of being stigmatized if their struggles with mental illness become apparent to others.

Finally, of the sociodemographic variables, only students' living arrangement was found to be a significant predictor of the severity of symptoms of depression (the variable was non-significant in the anxiety model). Our research findings here run contrary to Buote et al.'s (2007) finding that living on campus led to positive mental health outcomes because of building strong social support systems with other students. We hypothesized that familial social support would have a buffering effect on the potential emergence of symptoms consistent with mental illness, particularly for those experiencing stress produced by environmental maladjustment (e.g., struggling to form new relationships). Results of the present study showed that living with family members off campus had a statistically significant, inverse relationship with the severity of symptoms of depression, as compared to other living arrangements (living on residence, near campus with friends, or off campus alone). Given the notable importance of strong social support networks in the previous literature (e.g., Byrd \& McKinney, 2012; Hefner \& Eisenberg, 2009; Irons \& Gilbert, 2005; Wilson \& Dean, 2010), this finding may indicate that the safety net of familial social support effectively mediates the severity of symptoms consistent with depression more so than the social support of friendships. It is also possible that students receive more functional social support from family members and more structural social support from friendships. Hefner and Eisenberg (2009) emphasized the importance of functional social support, finding that the positive effects of social support were the most effective when the support provided was highly functional.

\section{Limitations and Future Directions}

Despite participants having been assured of both confidentiality and anonymity, bias resulting from self-reported data as well as social desirability may have influenced the results of our study. Additionally, the conceptual model used for the purposes of this study outlines a linear relationship, namely stress devolving into a state of distress (e.g., symptoms of mental illness) based on the mediating effects of contextual stressors, coping strategies, and perceived barriers to help-seeking. Future research should investigate the possibility of a multidirectional relationship between distress and coping strategies and perceived barriers to help-seeking. It is possible that struggling with a mental illness such as anxiety or depression may inflate perceived barriers to help-seeking, and produce a greater tendency towards the use of maladaptive coping strategies.

Taken together, the predictors included in our analyses account for $63 \%$ and $60 \%$ of the total variance in the severity of symptoms consistent with depression and anxiety, respectively. While both models are strong, there remain other predictors that require attention in future studies. One such predictor is the lack of awareness and education surrounding the recognition of mental illnesses, as well as a lack of knowledge of available treatment options (Wilson \& Dean, 2010). Several researchers have suggested that an inadequate level of mental health literacy may be leading students to believe that their poor mental state is a result of the normal stresses associated with postsecondary life (e.g., Eisenberg, Golberstein, et al., 2007; Wilson \& Dean, 2010; Wyatt \& Oswalt, 2013). This finding is concerning, given that this misconception may be contributing towards the low rate of help-seeking among students. Additionally, researchers (e.g., Kuss, Griffiths, \& Binder, 2013; Young, 2004) have suggested that students often demonstrate an overreliance on technology, and in some cases may suffer from Internet addiction. Given that mental/behavioral disengagement had the greatest impact on students' mental health outcomes in our study, future research should explore students' overreliance on, and disengagement through technology as a maladaptive coping strategy. Finally, the present study did not explore social psychologic measures such as self-efficacy, self-esteem, or self-confidence, all of which have been identified in previous 
research as significant predictors of an individual's ability to cope effectively. Future research should incorporate these personality measures to achieve a well-rounded analysis of coping abilities and strategies.

Due to scope restraints, our study examined symptoms of only two broadly defined mental illnesses common to student populations: anxiety and depression. As a variety of mental health issues affect students, future research should work towards addressing additional challenges (e.g., eating, sleep, and substance abuse disorders). While several sociodemographic variables were collected from our sample, only five were included in the multivariate analyses. Due to the limited variability in our sample, sociodemographic variables were heavily skewed to more dominant groups (e.g., heterosexual, Caucasian, non-religious, etc.) and thus, inclusion of many of these variables in the analyses would not have been informative. The sociodemographics ultimately included in our analyses were selected based on their importance in the relevant literature and the findings of previous studies. It is likely that additional sociodemographics (e.g., race/ethnicity, sexual orientation, religiosity, etc.), particularly those characterizing non-dominant groups, would have a significant impact on the prediction of students' mental health outcomes. Therefore, more comprehensive future research should investigate these important variables. Additionally, only one of the sociodemographic variables included in our analyses was statistically significant. This is most likely due to our limited sample size: A larger study would be better powered to detect statistical significance in a greater number of sociodemographic variables.

Finally, the screening tools used to evaluate symptoms of depression and anxiety in this study were used as indices of symptom severity, and not as tools for clinical diagnosis of mental illness. It is important to note that while both the PHQ-9 and GAD-7 have been deemed appropriate for use as severity indices (Kroenke et al., 2001; Kroenke \& Spitzer, 2002; Spitzer et al., 2006); a high score on a symptom severity index does not necessarily indicate a diagnosable mental illness. Finally, it is also important to acknowledge that the time of year during which survey completion took place, near midterm examinations, may have contributed to spikes in symptoms consistent with anxiety and depression, artificially inflating students' scores on both the PHQ-9 and GAD-7.

\section{Conclusion}

While the findings of this study should not be used to make definitive claims about the state of all Canadian postsecondary students' mental health, the conclusions drawn here will contribute to the Canadian body of knowledge on postsecondary students' mental health. Growing this knowledge base is essential for the development of successful mental health services and literacy education programs provided by Canadian postsecondary institutions. Although the data in our study is bound to the convenience sample of students at this university, general trends and themes may be applicable to larger, more comprehensive studies in the future, particularly given that the findings of this study parallel those of previous research. Future research should work towards extending this line of research to larger student samples, and replicating these findings across diverse university environments to better understand the average Canadian postsecondary student's social context and to gain clarification of the factors affecting students' mental health outcomes.

Additionally, several scales used to measure concepts in the current study are becoming outdated. In particular, the creation of a new scale tool for measuring students' perceptions of contextual stressors would be useful for future research. To develop a comprehensive inventory of potential stressors that are significant for students, we recommend a "for students by students" development approach, as employed by Park et al. (2012) in the development of the Mental Health Treatment Fears and Obstacles (MHTFO) inventory, a version of which was utilized in our study. Through this 
method, student participants are first asked to respond to one or two targeted, open-ended questions that prompt them to provide answers that are qualitatively analyzed and organized into a large inventory of items. This inventory is then rereleased to participants in a scaled question format, and the resulting data factor analyzed to determine the strongest items, as well as the reliability and validity of the tool.

Despite several Canadian universities' proposed strategic initiatives targeted at raising awareness and decreasing stigma, as well as fostering supportive postsecondary environments, an unmet need for treatment continues to exist among student populations, and reports of increasing prevalence of symptoms consistent with mental illness among students continue to come to light. Additionally, the apparent prevalence and severity of symptoms consistent with mental illness among this population continues to rise according to reports from university counseling centers (e.g., Gallagher, 2013). Canadian postsecondary institutions' movements towards the encouragement and support of students struggling with mental illnesses needs to continue to develop stigma-free environments where open discussion of mental health is welcomed. It is imperative that both faculty and students are aware of how to recognize deteriorating mental health as well as symptoms consistent with mental illness, and have active knowledge of the resources available to encourage healthy and effective help-seeking behavior among peers. Based on the findings of our study, students perceived there to be several contextual stressors within the postsecondary setting, and struggled most with time/balance issues. Universities should continue to provide struggling students with guidance directed towards developing organizational skills and the ability to balance multiple obligations. To deliver these services, however, students must first be encouraged to seek help when needed. A movement away from mental and behavioral disengagement as a coping mechanism needs to be addressed and conveyed to undergraduate students across Canada. In support of this, the continued development and implementation of anti-stigma initiatives, as well as renewed commitment to encouraging informed mental health literacy throughout postsecondary institutions must be priorities moving forward.

Previous studies have indicated a prevalence of stress and other overwhelming feelings among postsecondary populations across North America (e.g., American College Health Association, 2016; Benton et al., 2003; Cook, 2007; Gallagher, 2013; Hyun et al., 2006; Mental Health Commission of Canada, 2013). Findings show students actively struggle with environmental maladjustment, feelings of homesickness, loneliness, and difficulty with managing the multiple demands of their academic, professional, and social lives (e.g., Buote et al., 2007; Byrd \& McKinney, 2012; Cook, 2007; Fritz \& DeMarinis, 2008; Government of Canada, 2006; Jackson et al., 2000; Oswald \& Clark, 2003; Pancer et al., 2000; Paul \& Brier, 2001; Whitehill et al., 2012). Through this study, we have begun to investigate these factors within a Canadian context, finding a considerable presence of symptoms consistent with anxiety and depression, along with significant perceived contextual stressors, use of maladaptive coping strategies, and perceived barriers to help-seeking at a single Canadian university. Given these empirical findings, in addition to the fact that suicide is currently the second leading cause of death among young Canadians aged 15 to 34 (Statistics Canada, 2012), it is imperative that future research continues to evaluate factors affecting postsecondary students' mental health outcomes, making the treatment and analysis of mental health issues among this population a policy priority for Canada. More comprehensive studies in the future should move Canada towards building a healthier future for postsecondary students. 


\section{References}

American College Health Association. (2016). American College Health Association - National College Health Assessment II: Canadian reference group data report. Retrieved from http://www.cacuss.ca/_Library/Provincial_Reports/NCHAII_SPRING_2016_CANADIAN_REFERENCE_GROUP_DATA_REPORT.p $d f$

Arnett, J. J. (2000). Emerging adulthood: A theory of development from the late teens through the twenties. American Psychologist, 55, 469-480.

Benton, S. A., Robertson, J. M., Tseng, W. C., Newton, F. B., \& Benton, S. L. (2003). Changes in counselling center client problems across 13 years. Professional Psychology: Research and Practice, 34, 66-72.

Billings, A. G., \& Moos, R. H. (1981). The role of coping responses and social resources in attenuating the stress of life events. Journal of Behavioural Medicine, 4, 139-157.

Buote, V. M., Pancer, S. M., Pratt, M. W., Adams, G., Lefcovitch, S. B., Polivy, J., \& Wintre, M. G. (2007). The importance of friends: Friendship and adjustment among 1st-year university students. Journal of Adolescent Research, 2, 665-689.

Burge, J. (2009). Coping frequency, coping effectiveness, and personality factors in university students (Unpublished honors thesis). University of Canberra, Canberra, Australia.

Byrd, D. R., \& McKinney, K. J. (2012). Individual, interpersonal, and institutional level factors associated with the mental health of college students. Journal of American College Health, 60, 185-193.

Carver, C. S., Scheier, M. F., \& Weintraub, J. K. (1989). Assessing coping strategies: A theoretically based approach. Journal of Personality and Social Psychology, 56, 267-283.

Cook, L. J. (2007). Striving to help college students with mental health issues. Journal of Psychosocial Nursing, 45, 40-44.

Crisp, A., Gelder, M., Goddard, E., \& Meltzer, H. (2005). Stigmatization of people with mental illnesses: A follow-up study within the changing minds campaign of the Royal College of Psychiatrists. World Psychiatry, 4, 106-113.

Doane, L. D., Gress-Smith, J. L., \& Breitenstein, R. S. (2015). Multi-method assessments of sleep over the transition to college and the associations with depression and anxiety symptoms. Adolescence, 44, 389-404.

Eisenberg, D., Golberstein, E., \& Gollust, S. E. (2007). Help-seeking and access to mental healthcare in a university student population. Medical Care, 45, 594-601.

Eisenberg, D., Gollust, S. E., Golberstein, E., \& Hefner, J. L. (2007). Prevalence and correlates of depression, anxiety, and suicidality among university students. American Psychological Association, 77, 534-542.

Eisenberg, D., Downs, M. F., Golberstein, E., \& Zivin, K. (2009). Stigma and help-seeking for mental health among college students. Medical Care Research and Review, 66, 522-541.

Ford, D. E., \& Cooper-Patrick, L. (2001). Sleep disturbances and mood disorders: An epidemiologic perspective. Depression and Anxiety, 14, 3-6. 
Fritz, M. V., Chin, D., \& DeMarinis, V. (2008). Stressors, anxiety, acculturation and adjustment among international and North American students. International Journal of Intercultural Relations, $32,244-259$.

Gallagher, R. P. (2013). National survey for counseling center directors. Retrieved from http://www.collegecounseling.org/wp-content/uploads/Survey-2013-4-yr-Directors-1.pdf

Garlow, S. J., Rosenburg, J., Moore, J. D., Haas, A. P., Koestner, B., Hendin, H., \& Nemeroff, C. (2008). Depression, desperation, and suicidal ideation in college students: Results from the American foundation for suicide prevention college screening project at Emory University. Depression and Anxiety, 25, 482-488.

Gillin, J. C. (1998). Are sleep disturbances risk factors for anxiety, depressive and addictive disorders? Acta Psychiatrica Scandinavica, 98, 39-43.

Givens, J. L., \& Tjia, J. (2002). Depressed medical students' use of mental health services and barriers to use. Academic Medicine, 77, 918-921.

Gore, F. M., Bloem, P. J. N., Patton, G. C., Ferguson, J., Joseph, V., Coffey, C., ... Mathers, C. D. (2011). Global burden of disease in young people aged 10-24 years: A systematic analysis. The Lancet, 377, 2093-2102.

Government of Canada. (2006). The human face of mental illness in Canada. (Catalogue no. HP5 19 /2006E). Retrieved from http://www.phac-aspc.gc.ca/publicat/humanhumain06/pdf/human_face_e.pdf

Healey, J. F., \& Prus, S. (2015). Statistics: A tool for social research (3rd edition). Toronto, Ontario, Canada: Nelson College Indigenous.

Hefner, J., \& Eisenberg, D. (2009). Social support and mental health among college students. American Psychological Association, 79, 491-499.

Hunt, J., \& Eisenberg, D. (2010). Mental health problems and help-seeking behaviour among college students. Journal of Adolescent Health, 46, 3-10.

Hyun, J. K., Quinn, B. C., Madon, T., \& Lustig, S. (2006). Graduate student mental health: Needs assessment and utilization of counseling Services. Journal of College Student Development, 47, 247-266.

Iarovici, D. (2014). Mental health issues and the university student. Baltimore, MD: Johns Hopkins University Press.

Irons, C., \& Gilbert, P. (2005). Evolved mechanisms in adolescent anxiety and depression symptoms: The role of the attachment and social rank systems. Journal of Adolescence, 28, 325-341.

Jackson, L. M., Pancer, S. M., Pratt, M. W., \& Hunsberger, B. E. (2000). Great expectations: The relation between expectancies and adjustment during the transition to university. Journal of Applied Social Psychology, 30, 2100-2125.

Jerema, C. (2010, July 8). Your grades will drop: How universities and high schools are setting students up for disappointment. Retrieved from http://www.macleans.ca/education/uniandcollege/your-grades-will-drop/

Johnson, E. O., Roth, T., \& Breslau, N. (2006). The association of insomnia with anxiety disorders and depression: Exploration of the direction of risk. Journal of Psychiatric Research, 40, 700 708. 
Kessler, R. C., Berglund, P., Borges, G., Nock, M., \& Wang, P. S. (2005). Trends in suicide ideation, plans, gestures, and attempts in the United States, 1990-1992 to 2001-2003. Journal of the American Medical Association, 293, 2487-2495.

Koball, H. L., Moiduddin, E., Henderson, J., Goesling, B., \& Besculides, M. (2010). What do we know about the link between marriage and health? Journal of Family Issues, 31, 1019-1040.

Kroneke, K., \& Spitzer, R. L. (2002). The PHQ-9: A new depression diagnostic and severity measure. Psychiatric Annals, 32, 509-521.

Kroneke, K., Spitzer, R. L., \& Williams, J. B. W. (2001). The PHQ-9: Validity of a brief depression severity measure. Journal of General Internal Medicine, 16, 606-613.

Kuss, D. J., Griffiths, M. D., \& Binder, J. F. (2013). Internet addiction in students: Prevalence and risk factors. Computers in Human Behavior, 29, 959-966.

Luxton, D. D., Skopp, N. A., \& Marguen, S. (2010). Gender differences in depression and PTSD symptoms following combat exposure. Depression and Anxiety, 27, 1027-1033.

Margolis, R., \& Myrskylä, M. (2010, August). Happiness and marital status: Globally and across contexts. Paper presented at the annual meeting of the American Sociological Association, Atlanta, GA.

Marshall, K. (2010). Employment patterns of postsecondary students. (Catalogue no. 75-001 X). Retrieved from http://www.statcan.gc.ca/pub/75-001-x/2010109/article/11341-eng.htm\#a2

Martin, R. J., Usdan, S., Cremeens, J., \& Vail-Smith, K. (2014). Disordered gambling and comorbidity of psychiatric disorders among college students: An examination of problem drinking, anxiety and depression. Journal of Gambling Studies, 30, 321-333.

Martinello, F. (2008). Student transitions and adjustments in Canadian postsecondary education. (MESA Project Research Paper 2008-7). Retrieved from http://www.mesaproject.org/research.php

Mental Health Commission of Canada. (2013). Making the case for investing in mental health in Canada. Retrieved from http://www.mentalhealthcommission.ca/sites/default/files/201606/Investing_in_Mental_Health_FINAL_Version_ENG.pdf

Moreno, M. A., Jelenchick, L. A., \& Kota, R. (2013). Exploring depression symptom references on Facebook among college freshman: A mixed methods approach. Open Journal of Depression, 2, 35-41.

Moerno, M. A., Jelenchick, L. A., \& Breland, D. J. (2015). Exploring depression and problematic Internet use among college females: A multisite study. Computers in Human Behavior, 49, 601-607.

Neuman, L. W., \& Robson, K. (2015). Basics of social research, 3rd edition. Ontario, Canada: Pearson Education Canada.

Noh, S., \& Kaspar, V. (2003). Perceived discrimination and depression: Moderating effects of coping, acculturation, and ethnic support. American Journal of Public Health, 93, 232-238.

Office of Research Planning. (2014). Fall undergraduate enrolment by student Cohort: 2014 fall term registration statistics Supplemental Report A. Retrieved from https://www.uregina.ca/orp/assets/statistics/supplemental-reports/z-archive-supreports/201430-sup-report-a.pdf

Oswald, D. L., \& Clark, E. M. (2003). Best friends forever? High school best friendships and the transition to college. Personal Relationships, 10, 187-196. 
Pallant, J. (2011). SPSS survival manual: A step by step guide to data analysis using the SPSS program (4th edition). Melbourne, Australia: Allen \& Unwin.

Pancer, S. M., Hunsberger, B., Pratt, M. W., \& Alisat, S. (2000). Cognitive complexity of expectations and adjustment to university in the first year. Journal of Adolescent Research, 15, 38-57.

Park, H. L., Attenweiler, W. J., \& Rieck, S. M. (2012). Creation of a mental health treatment fears and obstacles inventory for college students. Journal of College Student Development, 53, $750-759$.

Parker, J. D. A., Summerfeldt, L. J., Hogan, M. J., \& Majeski, S. A. (2004). Emotional intelligence and academic success: Examining the transition from high school to university. Personality and Individual Differences, 36, 163-172.

Paul, E. L., \& Brier, S. (2001). Friendsickness in the transition to college: Precollege predictors and college adjustment correlates. Journal of Counseling and Development, 79, 77-89.

Pearlin, L. I., Menaghan, E. G., Lieberman, M. A., \& Mullan, J. T. (1981). The stress process. Journal of Health and Social Behavior, 22, 337-356.

Pearson, C., Janz, T., \& Ali. J. (2013). Mental and substance use illnesses in Canada. (Catalogue no. 82-624-X). Retrieved from http://www.statcan.gc.ca/pub/82-624-x/2013001/article/11855eng.htm\#n12

Rosenthal, B., \& Wilson, W. C. (2008). Mental health services: Use and disparity among diverse college students. Journal of American College Health, 57, 61-67.

Rosemann, T, Backenstrauss, M., Josest, K., Rosemann, A., Szecsenyi, J., \& Laux, G. (2007). Predictors of depression in a sample of 1,021 primary care patients with osteoarthritis. Arthritis \& Rheumatism, 57, 415-422.

Spitzer, R. L., Kroenke, K., Williams, J. B.W., \& Löwe, B. (2006). A brief measure for assessing generalized anxiety disorder: the GAD-7. Archive of Internal Medicine, 166, 1092-1097.

Statistics Canada. (2015). Table 477-0033 Postsecondary enrolments, by program type, credential type, age groups, registration status and sex, annual (2013-2014). [Data file]. Retrieved from http://www5.statcan.gc.ca/cansim/a26?lang = eng\&id $=4770033$

Statistics Canada. (2013). Table 105-1101 Mental Health Profile, Canadian Community Health Survey - Mental Health (CCHS), by age group and sex, Canada and provinces. [Data file]. Retrieved from http://www5.statcan.gc.ca/cansim/a26?lang = eng\&id = 1051101

Statistics Canada. (2012). Suicide rates: An overview. (Catalogue no. 82-624-X). Retrieved from http://www.statcan.gc.ca/pub/82-624-x/2012001/article/11696-eng.htm

Sunderland, A., \& Findlay, L. C. (2013). Perceived need for mental health care in Canada: Results from the 2012 Canadian Community Health Survey - Mental Health. (Catalogue no. 82-003$\mathrm{X})$. Retrieved from http://www.statcan.gc.ca/pub/82-003-x/2013009/article/11863-eng.pdf

Tabachnick, B. G., \& Fiddell, L. S. (2012). Using multivariate statistics (6th edition). Toronto, Canada: Pearson.

Taylor, S. E., \& Stanton, A. L. (2007). Coping resources, coping processes, and mental health. Annual Review of Clinical Psychology, 3, 377-401.

Wheaton, B., Young, M., Montazer, S., \& Stuart-Lahman, K. (2013). Social stress in the twenty-first century. In C. S. Aneschensel, J. C. Phelan, \& A. Bierman (Eds.), Handbook of the sociology of mental health (pp. 229-324). New York, NY: Springer.

Whiteford, H. A., Defenhardt, L., Rehm, J., Baxter, A. J., Ferrari, A. J., Erskine, H. E., ... Vos, T. 
(2013). Global burden of disease attributable to mental use disorders: findings from the Global Burden of Disease Study 2010. The Lancet, 382, 1575-1586.

Whitehill, J. M., Brockman, L. N., \& Moreno, M. A. (2012). Just talk to me: Communicating with college students about depression disclosures on Facebook. Journal of Adolescent Health, 52, $122-127$.

Wilson, C. J., \& Deane, F. P. (2010). Help-negation and suicidal ideation: The role of depression, anxiety and hopelessness. Journal of Youth and Adolescence, 39, 291-305.

Wilson, K. T., Bohnert, A. E., Ambrose, A., Davis, D. Y., Jones, D. M., \& Magee, M. J. (2014). Social, behavioral, and sleep characteristics associated with depression symptoms among undergraduate students at a women's college: a cross-sectional depression survey, 2012. BMC Women's Health, 14, 1-9.

Wood, R. G., Goesling, B., \& Avellar, S. (2007). The effects of marriage on health: A synthesis of recent research evidence. Retrieved from http://aspe.hhs.gov/sites/default/files/pdf/75106/report.pdf

World Health Organization. (2013). Mental health action plan 2013-2020. Retrieved from http://apps.who.int/iris/bitstream/10665/89966/1/9789241506021_eng.pdf

Wyatt, T., \& Oswalt, S. B. (2013). Comparing mental health issues among undergraduate and graduate students. American Journal of Health Education, 44, 96-107.

Young, K. S. (2004). Internet addiction: A new clinical phenomenon and its consequences. The American Behavioral Scientist, 48, 402-415. 


\section{Appendix}

Ordered Logistic Regression Effects of Selected Predictors on the Severity of Self-Reported Symptoms Consistent with Depression and Anxiety by Cut-Points

\begin{tabular}{|c|c|c|c|c|c|c|}
\hline & \multicolumn{3}{|c|}{$\begin{array}{c}\text { Severity of Depression } \\
\text { Cut-Points }\end{array}$} & \multicolumn{3}{|c|}{$\begin{array}{c}\text { Severity of Anxiety } \\
\text { Cut-Points }\end{array}$} \\
\hline & Estimate & $S E$ & Wald & Estimate & $S E$ & Wald \\
\hline Threshold 1 & -1.442 & 0.918 & 2.466 & -2.293 & 1.186 & 3.738 \\
\hline Threshold 2 & 0.801 & 0.904 & 0.785 & 0.307 & 1.159 & 0.070 \\
\hline Threshold 3 & $2.977^{* *}$ & 0.944 & 9.957 & $2.408^{*}$ & 1.189 & 4.101 \\
\hline Threshold 4 & $5.397 * * *$ & 1.046 & 26.642 & - & - & - \\
\hline \multicolumn{7}{|l|}{ Sociodemographic factors } \\
\hline Age & 0.006 & 0.037 & 0.029 & 0.010 & 0.039 & 0.060 \\
\hline \multicolumn{7}{|l|}{ Sex } \\
\hline Male (r) & 0.000 & & & 0.000 & & \\
\hline Female & 0.629 & 0.426 & 2.180 & -0.566 & 0.442 & 1.635 \\
\hline \multicolumn{7}{|l|}{ Marital status } \\
\hline Single (r) & 0.000 & & & 0.000 & & \\
\hline Married & -0.226 & 0.483 & 0.218 & -0.292 & 0.500 & 0.341 \\
\hline \multicolumn{7}{|l|}{ Living arrangement } \\
\hline Other $(\mathrm{r})$ & 0.000 & & & 0.000 & & \\
\hline With family & $-1.180 * *$ & 0.344 & 11.748 & 0.370 & 0.349 & 1.124 \\
\hline Year of study & 0.222 & 0.144 & 2.365 & 0.001 & 0.149 & 0.000 \\
\hline \multicolumn{7}{|l|}{ Contextual stressors } \\
\hline Social/Environmental & $0.722 * * *$ & 0.162 & 19.873 & $0.622 * * *$ & 0.172 & 13.101 \\
\hline Academic achievement & $0.677 * * *$ & 0.171 & 15.621 & $0.669 * * *$ & 0.175 & 14.624 \\
\hline Curriculum/Expectations & $0.435^{* *}$ & 0.165 & 6.966 & $0.385^{*}$ & 0.169 & 5.201 \\
\hline Time/Balance & $0.551^{* * *}$ & 0.170 & 10.540 & $0.637 * * *$ & 0.179 & 12.691 \\
\hline Financial stressors & $0.350 *$ & 0.154 & 5.160 & $0.376^{*}$ & 0.161 & 5.466 \\
\hline \multicolumn{7}{|l|}{ Coping mechanisms } \\
\hline Functional/Adaptive & -0.226 & 0.163 & 1.917 & $0.408^{*}$ & 0.175 & 5.453 \\
\hline $\begin{array}{l}\text { Mental/Behavioral } \\
\text { Disengagement }\end{array}$ & $1.148^{* * *}$ & 0.206 & 30.912 & $1.156^{* * *}$ & 0.234 & 24.447 \\
\hline Substance abuse & $0.696^{* * *}$ & 0.161 & 18.588 & $0.397^{*}$ & 0.158 & 6.316 \\
\hline \multicolumn{7}{|l|}{ Barriers to help-seeking } \\
\hline Fear of therapy & $0.466^{* *}$ & 0.159 & 8.634 & $0.399^{*}$ & 0.173 & 5.344 \\
\hline Fear of self-discovery & $0.550 * *$ & 0.179 & 9.450 & 0.258 & 0.191 & 1.829 \\
\hline Fear of stigma & -0.022 & 0.156 & 0.020 & -0.146 & 0.167 & 0.764 \\
\hline \multicolumn{7}{|l|}{ Test of parallel lines } \\
\hline-2 log likelihood $\left(\chi^{2}, d f\right)^{\operatorname{Sig}}$ & \multicolumn{3}{|c|}{$354.79(23.87,48)^{n . s .}$} & \multicolumn{3}{|c|}{$333.37(7.24,32)^{n . s .}$} \\
\hline \multicolumn{7}{|l|}{ Model fitting } \\
\hline-2 log likelihood $\left(\chi^{2}, d f\right)^{\operatorname{Sig}}$ & \multicolumn{3}{|c|}{$378.66(164.83,16)^{* * *}$} & \multicolumn{3}{|c|}{$340.61(148.78,16)^{* * *}$} \\
\hline \multicolumn{7}{|l|}{ Goodness-of-fit test } \\
\hline Pearson $\chi^{2}(d f)^{\mathrm{Sig}}$ & \multicolumn{3}{|c|}{$528.12(696)^{n . s .}$} & \multicolumn{3}{|c|}{$583.97(518)^{n . s .}$} \\
\hline \multicolumn{7}{|l|}{ Pseudo- $R^{2}$} \\
\hline Cox and Shell & \multicolumn{3}{|c|}{0.602} & \multicolumn{3}{|c|}{0.564} \\
\hline Nagelkerke & \multicolumn{3}{|c|}{0.632} & \multicolumn{3}{|c|}{0.604} \\
\hline
\end{tabular}

Note. $(\mathrm{r})=$ reference category; ${ }^{\text {n.s. }}=$ not statistically significant.

${ }^{*} p<.05 .{ }^{* *} p<.01 .{ }^{* * *} p<.001$. 
The Journal of Social, Behavioral, and Health Sciences is an open-access, peer-reviewed, online interdisciplinary journal focusing on research findings that address contemporary national and international issues. Its objectives are to (a) encourage dialogue between scholars and practitioners in the social, behavioral, and health sciences that fosters the integration of research with practice; (b) promote innovative models of interdisciplinary collaboration among the social, behavioral, and health sciences that address complex social problems; and (c) inform the relationship between practice and research in the social, behavioral, and health sciences.

Walden University Publishing: http://www.publishing.waldenu.edu 